\title{
Impact of Recreational Sports Activities on Metabolic Syndrome Components in Adolescents
}

\author{
Fernanda Faria ${ }^{1, *(1)}$, Cheryl Howe ${ }^{2}$, Ricardo Faria ${ }^{3}$, Alynne Andaki ${ }^{4}$, João Carlos Marins ${ }^{1}$ and \\ Paulo Roberto Amorim ${ }^{1}$ \\ 1 Department of Physical Education, Federal University of Viçosa, Viçosa, Minas Gerais 36570-900, Brazil; \\ jcbouzas@ufv.br (J.C.M.); pramorim@ufv.br (P.R.A.) \\ 2 School of Applied Health Sciences and Wellness, Ohio University, Athens, OH 45701, USA; howec@ohio.edu \\ 3 Department of Physical Education, Federal Institute of Education, Science and Technology of the Southeast \\ of Minas Gerais, Rio Pomba, Minas Gerais 36180-000, Brazil; ricardoefi@yahoo.com.br \\ 4 Department of Sport Science, Federal University of Triângulo Mineiro, Uberaba, \\ Minas Gerais 38025-180, Brazil; alynne.andaki@uftm.edu.br \\ * Correspondence: frfaria.ef@gmail.com
}

Received: 4 November 2019; Accepted: 23 December 2019; Published: 24 December 2019

\begin{abstract}
We investigated the impact of a sports activities program on metabolic syndrome (MetS) components and pre-MetS among adolescents. Blood samples, blood pressure, weight, height, body mass index, waist circumference, body fat percentage, frequency of food consumption, daily time in moderate-to-vigorous physical activity (MVPA), and sedentary behavior (SB) of 92 male adolescents aged $14-18$ years $(16.07 \pm 0.93)$ were evaluated. From this initial sample, 36 participants $(39.1 \%)$ were diagnosed with pre-MetS or MetS and were invited to participate in the intervention program. Twelve individuals diagnosed with pre-MetS or MetS agreed to participate in a recreational sports activities program lasting 14 weeks. The pre- and post-sport program comparison showed a reduction in total cholesterol, low-density lipoprotein, and non-high-density lipoprotein (HDL), and an increase in HDL and MVPA time in the intervention group. Sports activities accounted for $42 \%$ of the MVPA daily recommendation, and at the end of the intervention period, only seven subjects maintained a positive diagnosis for pre-MetS or MetS. This study showed that recreational sports activities had a significant impact on the lipid profile.
\end{abstract}

Keywords: accelerometer; adolescent; lifestyle; metabolic syndrome; obesity

\section{Introduction}

The increase in the prevalence of obesity and hypertension among children and adolescents is considered a public health problem with severe epidemiological and economic implications [1], and it has favored the emergence of the metabolic syndrome (MetS) in this population [2].

MetS is often defined as the clustering of three or more risk factors. It can include adiposity, hyperglycemia, hypertension, hypertriglyceridemia, and lower high-density lipoprotein (HDL) [3]. The MetS prevalence in Brazilian adolescents ranges from 2.6\% [4] to 6.7\% [5], possibly reaching $37.1 \%$ [5] among overweight or obese adolescents. It is critical to highlight that the prevalence of any disease or syndrome relies on the criteria being used to diagnose the disease or syndrome. However, there is no consensus on the criteria used for diagnosing MetS in adolescents [6].

Using the adult criteria, the significant rates of this disorder in the pediatric population indicate the need for early diagnosis to avoid future complications in general health $[7,8]$. Thus, a new approach to the adult metabolic profile evaluation has been suggested through the identification of pre-MetS. The pre-MetS is characterized by having two of the risk factors associated with the MetS period $[9,10]$. 
Pre-MetS and MetS are significantly and negatively associated with reduced physical activity and increased time spent in sedentary behavior (SB) [11]. Physical activity is considered an essential component of a healthy lifestyle and must be incorporated in everyday living as a primary strategy to prevent disease [12]. It is recommended that adolescents engage in 60 min daily of moderate-to-vigorous physical activity (MVPA) or more to obtain health benefits [13]. Simultaneously, time spent in SB-activities carried out in a sitting position, such as sitting in front a TV or computer or playing traditional videogames-is associated with high body fat percentage and MetS prevalence among adolescents [14], independent of the physical activity levels [15].

Considering the focus on lifestyle changes, multidisciplinary interventions (diet and physical activity) directed to adolescents have been conducted to reduce obesity and its comorbidities, including MetS [6,16-18]. However, we have not found in the literature whether recreational sports activities, which are easily applicable in the school context, are more motivating and have a higher adherence among young people, reflecting positively on the control of MetS risk factors. Thus, the objective of this study was to evaluate the impact of a recreational sports program on the components of pre-MetS and MetS in Brazilian adolescents.

\section{Materials and Methods}

\subsection{Participants and Ethical Aspects}

The sample consisted of students recruited from a full-time federal institution of technical education from the county of Rio Pomba, Minas Gerais, Brazil; according to the following inclusive criteria: to be a male resident high school student, living on the campus of the school; between 14 and 18 years of age. Of the approximately 500 students enrolled in the first, second, and third years of high school, 109 were considered eligible; however, 17 students did not perform the necessary assessments for the study. Thus, the MetS components were evaluated in a sample composed of 92 individuals. From this number, 36 were diagnosed with pre-MetS or MetS and were invited to participate in the activities program, with the final acceptance of 12 students. In this second phase, the exclusion criteria included the use of medications to control blood pressure, fasting glucose, or lipid metabolism, other previously diagnosed chronic diseases besides MetS, permanent or temporary physical disability, and caloric restriction diet.

The research project was submitted and approved by the Human Research Ethics Board from the Federal University of Viçosa (Off. Ref. No. 177.176/2013/CEPH), following the Resolution 466/12 of the National Health Council and following the Declaration of Helsinki. All the participants were volunteers and signed the informed assent form, while parents of the participants under the age of 18 signed the informed parental consent.

\subsection{Procedure}

The study's first phase is related to a pre-MetS and MetS cross-sectional baseline screening, while the second phase consisted of a longitudinal quasi-experimental study with the participation of 12 students (10 with pre-MetS and 2 with MetS) in a 14 week recreational sports program.

In the first phase, all 92 students were evaluated for body composition, maturation status, eating habits, resting vitals, physical activity, SB, and MetS components, before the beginning of the program. Of the initial 92 students, the 12 participants in the intervention program also had their resting heart rate monitored to estimate the maximal heart rate. During the 13th week of the intervention, participants enrolled in the second phase had their physical activity and SB evaluated again, while the other evaluations were performed in the 14th week.

\subsection{MetS Components}

After fasting for 12-14 h, morning blood samples were collected in the healthcare sector of the institution, by qualified and trained professionals, designated by the accredited laboratory to conduct 
the analyzes. We collected $5 \mathrm{~mL}$ of blood from the cubital vein and then centrifuged it at $3400 \mathrm{rpm}$ for five minutes to separate serum from other blood components. The levels of fasting glucose, total cholesterol, HDL, and triglycerides were determined through enzymatic colorimetric assay method, while insulin level was analyzed using the electrochemiluminescence method. The equipment used for the blood tests was the biochemical analyzer Awareness Technology ${ }^{\circledR}$ (model ChemWell-T, Palm City, Florida, USA).

MetS and the cutoff points used for each of its components were defined according to De Ferranti et al. [19], which considers the presence of three or more of the following criteria: triglycerides concentration $>100 \mathrm{mg} / \mathrm{dL}$; fasting glucose $>110 \mathrm{mg} / \mathrm{dL}$; waist circumference $>75$ th percentile for age and sex; blood pressure $>90$ th percentile for age, sex, and height; and HDL cholesterol $<45 \mathrm{mg} / \mathrm{dL}$. Pre-MetS was defined by the presence of two of these components [10].

Insulin resistance was evaluated by homeostatic model assessment (HOMA-IR), according to the equation proposed by Matthews et al. [20], and low-density lipoprotein (LDL) by the Friedewald et al. [21] equation. The non-HDL cholesterol determination occurred through the formula proposed by Srinivasan et al. [22]. The cutoff points adopted for the HOMA-IR and LDL index were those recommended by the Guidelines for the Prevention of Atherosclerosis in Childhood and Adolescence [23]; for insulin, the values established by Ten and McLaren [24] were used; and for non-HDL the recommendation of Srinivasan et al. [22] was applied.

\subsection{Anthropometry and Body Composition}

Anthropometric measures (height and weight) and skinfolds were performed according to procedures standardized by the International Society for the Advancement of Kinanthropometry [25]. All measurements were duplicated, and a third measurement was performed if the technical error of measurement was exceeded [25]. Weight was obtained to the nearest $0.05 \mathrm{~kg}$ using a calibrated digital scale Líder ${ }^{\circledR}$ (model Leader P-200c, Araçatuba, São Paulo, Brazil) and height to the nearest $0.1 \mathrm{~cm}$ using a portable stadiometer Sanny ${ }^{\circledR}$ (model Personal Caprice, São Paulo, Brazil). The body mass index (BMI) was calculated from the $\mathrm{kg} / \mathrm{m}^{2}$ ratio, and the cutoff points proposed by the World Health Organization (WHO) were used to classify weight status [26].

Waist circumference was obtained from two distinct anatomical points, including the measurement in the region of the smallest waist circumference (SWC) [25], as well as in the midpoint between the last rib and the iliac crest (MWC) [27]. Circumference measurements were performed by the use of a flexible and inelastic metallic anthropometric tape, graduated in centimeters, and subdivided in millimeters Sanny ${ }^{\circledR}$ (São Paulo, Brazil). Subsequently, the waist-to-height ratio was calculated.

Body fat percentage was estimated by the Slaughter et al. [28] equation, from the sum of triceps and medial calf skinfold $(\mathrm{mm})$ using a calibrated caliper with $1 \mathrm{~mm}$ precision and $67 \mathrm{~mm}$ amplitude Lange ${ }^{\circledR}$ (model TBW, Maryland, USA). The value of $20 \%$ as an indicator of body fat excess was used as recommended by Going et al. [29].

\subsection{Maturational Evaluation}

The maturational stage was obtained through the peak height velocity using the equation and the classification suggested by Mirwald et al. [30], which considers leg and trunk lengths, age, weight, and height. Peak height velocity was classified into three groups: pre-pubertal (peak height velocity $\leq-1$ ), pubertal (peak height velocity $=0$ ), or post-pubertal (peak height velocity $\geq 1$ ).

\subsection{Resting Blood Pressure}

Blood pressure was measured three times, after a period of 5-10 min at rest; and at least 1 min between measurements. Blood pressure was considered the average value from the last two measurements, according to the protocol proposed by the Guidelines for the Prevention of Atherosclerosis in Childhood and Adolescence [23]. The measure was performed by a certified and trained evaluator using a mercury column sphygmomanometer to the nearest $2 \mathrm{mmHg}$ and a range of 
10-300 mmHg (Unitec ${ }^{\circledR}$, São Paulo, Brazil), a stethoscope Premium ${ }^{\circledR}$ (model Rapport model, Rio de Janeiro, Brazil) and suitable cuff size for adolescents.

\subsection{Resting Heart Rate}

Before the beginning of the intervention activities, each participant had their resting heart rate evaluated. The student was taken to the evaluation room and asked to remain at rest, in the lying position, for $10 \mathrm{~min}$. The lowest heart rate recorded in this period was used as the resting heart rate. The maximal heart rate was estimated using the Tanaka et al. [31] formula.

\subsection{Eating Habits}

The participant's eating habits were assessed using a Food Frequency Questionnaire, adapted from a regional model, with the addition of types of food provided by the institutional refectory. The items included in the questionnaire were: bread, pasta, cereal, tuber, vegetables, fruits, meat, sausage, egg, sugar, sweets, snacks, oils, fats, and seasonings. Participants were instructed to fill out the number of times per week and per day in which they consumed a particular food group. As all the participants were resident students, most of the food consumption made for them was prepared by the school cafeteria. Then, to facilitate the completion of the questionnaire, we provided a spreadsheet with the average number of times per week each food group was served. Two nutritionists reviewed the forms as they were completed for accuracy.

\subsection{Physical Activity and Sedentary Behavior}

Physical activity and SB were assessed using a triaxial accelerometer Actigraph ${ }^{\circledR}$ (GT3X model, Florida, USA). Participants received the accelerometer and were instructed to wear it at the waist, toward the midline of the thigh, on the right side of the body, near the iliac crest. The accelerometer was worn for seven consecutive days and removed only during aquatic activities (i.e., bath, swimming, and related activities) and during sleep time. The data collection was considered valid for participants who recorded at least $10 \mathrm{~h}$ of daily use, in at least 4 weekdays and 1 weekend day [32]. The accelerometer was initialized at $30 \mathrm{~Hz}$, and its data were converted to $10 \mathrm{~s}$ epochs using ActiLife 5.0 software (Actigraph ${ }^{\circledR}$, Florida, USA). The activity intensity classification was based on the cutoff points proposed by Puyau et al. [33], which stratifies physical activity behavior into four distinct categories: $\mathrm{SB}<800$; light activity $\leq 3199$; moderate activity $\leq 8199$; and vigorous activity $\geq 8200$ counts/min.

Total daily energy expenditure was estimated from the proposed equation of the National Academy of Sciences Institute of Medicine Food and Nutrition Board for boys aged 3-18 years [34]. To calculate the result, we used a formula that includes age, physical activity level, weight, and height. The basal metabolic rate was estimated by the Schofield equation [35].

\subsection{Intervention}

Participants were asked to attend intervention sessions regularly. Interventions were constituted of popular recreational sports in Brazil, including volleyball, basketball, soccer, and futsal modalities, practiced 4 days a week, lasting $1 \mathrm{~h}$ each. Futsal modality was offered in two weekly sessions. Volleyball and basketball were provided during the same session for similar durations of two times per week. Every 15 days, the volleyball/basketball session was replaced by a five-a-side soccer game.

Participants wore heart rate monitors Garmin ${ }^{\circledR}$ with the Global Positioning System (Forerunner 610 model, Kansas, USA) to determine the intensity reached during intervention activities. The average session intensity was identified using the heart rate reserve method, calculated from the difference between resting heart rate and maximal heart rate, according to the following formula: heart rate reserve $\%=((\mathrm{AHR}-$ resting heart rate $) /$ heart rate reserve $) * 100$; in which AHR means the average heart rate during the intervention session.

The program lasted 14 weeks for a total of 56 sessions, and adolescents were asked to attend at least $70 \%$ of the total session number ( 29 sessions). A physical education teacher performed the 
intervention and was responsible for the sports practice organization, division of teams, sports rules adaptation when necessary, and activity time control.

\subsection{Statistical Analysis}

The variables were checked for normality of distribution using Kolmogorov-Smirnov and Shapiro-Wilk tests for the first and second phases of the study, respectively. The linear regression model was applied to evaluate the association among adiposity, metabolic, hemodynamic, and anthropometric variables. Log transformations were used to normalize non-parametric data of triglycerides, HOMA-IR, and insulin. According to the data distribution, Student's t-test or Mann-Whitney test was applied for independent samples. Moreover, in agreement with the distribution, paired Student t-test or Wilcoxon was used to evaluating possible differences in pre- and post-intervention variables. The effect size for the comparison tests was calculated using a specific formula. All statistics were performed using SPSS 20.0 (IBM Corporation, Armonk, NY, USA), and significance was set at $p<0.05$.

\section{Results}

In the first phase of the study carried out with 92 participants, we found a pre-MetS and MetS prevalence of $34.8 \%(n=32)$ and $4.3 \%(n=4)$, respectively. The individuals characterized with the pre-MetS or MetS were mostly (72.2\%) in post-pubertal maturation stage, $27.8 \%$ were classified as pubescent, and no individual was classified as pre-pubertal. Tables 1 and 2 represent the components initially evaluated for diagnosing pre-MetS or MetS. Regarding the anthropometric variables, participants with pre-MetS or MetS had higher weight $(p=0.004)$, BMI $(p=0.021)$, MWC $(p=0.030)$, and SWC $(p=0.025)$. Similarly, significantly higher values were found for systolic blood pressure $(p=0.005)$, diastolic blood pressure $(p=0.002)$, insulin $(p=0.049)$, HOMA-IR $(p=0.000)$, triglycerides $(p=0.000)$, and non-HDL $(p=0.000)$ in the pre-MetS and MetS groups (Table 1). No significant differences were found in time spent on MVPA and SB between groups, while basal metabolic rate was significantly higher in subjects with pre-MetS or MetS ( $p=0.004)$ (Table 2).

Table 1. Participants' metabolic, anthropometric, and hemodynamic profile, with and without metabolic syndrome or pre-metabolic syndrome.

\begin{tabular}{|c|c|c|c|c|c|}
\hline Variables & $\begin{array}{c}\text { Total } \\
(n=92)\end{array}$ & $\begin{array}{l}\text { No Pre-MetS or MetS } \\
\qquad(\mathrm{n}=56)\end{array}$ & $\begin{array}{l}\text { Pre-MetS or } \\
\text { MetS }(n=36)\end{array}$ & $p$ Value & ES \\
\hline Age (years) * & $16.0(14.0-18.0)$ & $16.0(14.0-18.0)$ & $16.0(14.0-18.0)$ & 0.287 & 0.11 \\
\hline Weight $(\mathrm{kg})$ * & $61.3(39.1-105)$ & $60.6(39.1-84.1)$ & $65.1(48.8-105)$ & $0.004^{+}$ & 0.30 \\
\hline Height (m) & $1.74( \pm 0.06)$ & $1.73( \pm 0.06)$ & $1.75( \pm 0.06)$ & 0.214 & 0.33 \\
\hline BMI $\left(\mathrm{kg} / \mathrm{m}^{2}\right)$ * & $20.5(15.1-33.9)$ & $20.2(15.1-25.1)$ & $21.2(16.8-33.9)$ & $0.021^{\dagger}$ & 0.24 \\
\hline WHtR * & $0.4(0.36-0.56)$ & $0.4(0.36-0.5)$ & $0.41(0.36-0.56)$ & 0.139 & 0.15 \\
\hline $\mathrm{BF} \% *$ & $13.4(7.2-41.4)$ & $13.5(7.9-26.6)$ & $12.5(7.2-41.4)$ & 0.914 & 0.01 \\
\hline $\operatorname{MWC}(\mathrm{cm}) *$ & $72.1(63.0-99.4)$ & $71.7(63.0-86.8)$ & 74.7 (64.5-99.4) & $0.030^{\dagger}$ & 0.23 \\
\hline $\operatorname{SWC}(\mathrm{cm}) *$ & $71.4(61.4-97.1)$ & $70.9(61.4-84.0)$ & $73.0(63.6-97.1)$ & $0.025^{+}$ & 0.23 \\
\hline SBP (mmHg) & $111.6( \pm 10.8)$ & $109.1( \pm 10.2)$ & $115.5( \pm 10.7)$ & $0.005^{+}$ & 0.61 \\
\hline $\mathrm{DBP}(\mathrm{mmHg})$ & $72.5( \pm 7.7)$ & $70.5( \pm 7.3)$ & $75.6( \pm 7.3)$ & $0.002^{+}$ & 0.70 \\
\hline HDL (mg/dL) & $42.9( \pm 8.6)$ & $45.8( \pm 8.9)$ & $38.3( \pm 5.9)$ & $0.000 \ddagger$ & 1.00 \\
\hline $\mathrm{TG}(\mathrm{mg} / \mathrm{dL}) *$ & $85(36-288)$ & $75.5(36-110)$ & $111(65-288)$ & $0.000 \ddagger$ & 0.64 \\
\hline $\mathrm{FG}(\mathrm{mg} / \mathrm{dL})$ & $77.8( \pm 7.5)$ & $77.1( \pm 7.1)$ & $78.9( \pm 8.0)$ & 0.248 & 0.25 \\
\hline Insulin $(\mathrm{mU} / \mathrm{L}) *$ & $4.8(1.4-28.5)$ & $4.4(1.4-21.0)$ & $6.09(1.9-28.5)$ & $0.049^{+}$ & 0.21 \\
\hline HOMA-IR * & $0.98(0.27-5.44)$ & $0.85(0.27-4.58)$ & $1.13(0.36-5.44)$ & $0.045^{+}$ & 0.21 \\
\hline $\mathrm{TC}(\mathrm{mg} / \mathrm{dL})$ & $159.6( \pm 23.6)$ & $155.4( \pm 22.8)$ & $166.2( \pm 23.5)$ & $0.031^{+}$ & 0.47 \\
\hline
\end{tabular}


Table 1. Cont.

\begin{tabular}{|c|c|c|c|c|c|}
\hline Variables & $\begin{array}{c}\text { Total } \\
(n=92)\end{array}$ & $\begin{array}{l}\text { No Pre-MetS or MetS } \\
\qquad(\mathrm{n}=56)\end{array}$ & $\begin{array}{c}\text { Pre-MetS or } \\
\text { MetS }(n=36)\end{array}$ & $p$ Value & ES \\
\hline LDL (mg/dL) & $97.6( \pm 19.4)$ & $94.4( \pm 18.3)$ & $102.6( \pm 20.4)$ & $0.048^{+}$ & 0.42 \\
\hline Non-HDL & $116.7( \pm 22.6)$ & $109.5( \pm 19.4)$ & $127.8( \pm 23.1)$ & $0.000 \ddagger$ & 0.86 \\
\hline \multicolumn{6}{|c|}{$\begin{array}{l}+p<0.05 ; \neq p<0.001 . \text { Note: } \mathrm{BMI}=\text { body mass index; WHtR }=\text { waist-to-height ratio; } \mathrm{BF} \%=\text { body fat } \% ; \\
\text { MWC = midpoint waist circumference; SWC = smallest waist circumference; SBP = systolic blood pressure; } \\
\text { DBP = diastolic blood pressure; HDL = high-density lipoprotein; TG = triglycerides; FG = fasting glucose; } \\
\text { HOMA-IR = Homeostatic Model Assessment; TC = total cholesterol; } \mathrm{LDL}=\text { low density lipoprotein; Non-HDL = not } \\
\text { HDL cholesterol; MetS = metabolic syndrome; ES = effect size. }{ }^{*} \text { Variables expressed as median (minimum and } \\
\text { maximum); other variables: average ( } \pm \text { standard deviation). }\end{array}$} \\
\hline
\end{tabular}

Table 2. Description of physical activity variables within physical and energy expenditure.

\begin{tabular}{|c|c|c|c|c|c|c|c|c|}
\hline Variables & $\mathbf{n}$ & Total Sample & $\mathbf{n}$ & $\begin{array}{c}\text { No Pre-MetS or } \\
\text { MetS }\end{array}$ & $\mathbf{n}$ & $\begin{array}{c}\text { Pre-MetS or } \\
\text { MetS }\end{array}$ & $p$ Value & ES \\
\hline MVPA (min/week) & 83 & $70.3( \pm 19.8)$ & 51 & $71.4( \pm 21.3)$ & 32 & $68.6( \pm 17.2)$ & 0.54 & 0.14 \\
\hline MVPA (min/weekday) & 83 & $76.5( \pm 20.8)$ & 51 & $77.3( \pm 22.0)$ & 32 & $75.3( \pm 19.2)$ & 0.67 & 0.10 \\
\hline MVPA (min/weekend day) * & 80 & $48.5(1.5-149.5)$ & 49 & $51.5(1.5-149.5)$ & 31 & $48(4.5-113)$ & 0.61 & 0.05 \\
\hline TEE (kcal/day) & 83 & $3095( \pm 582)$ & 51 & $3004( \pm 472)$ & 32 & $3240( \pm 708)$ & 0.11 & 0.40 \\
\hline $\operatorname{BMR}(\mathrm{kcal} /$ day $) *$ & 92 & $1743(1350-2516)$ & 56 & $1730(1350-2145)$ & 36 & $1810(1521-2516)$ & $0.004^{+}$ & 0.30 \\
\hline
\end{tabular}

${ }^{+} p<0.01$. Note: MVPA = moderate-to-vigorous physical activity; TEE = total energy expenditure; BMR = basal metabolic rate; MetS = metabolic syndrome; ES = effect size. ${ }^{*}$ Variables expressed as median (minimum and maximum); other variables: mean ( \pm standard deviation).

Table 3 depicts only the significant associations found between central adiposity measures and metabolic variables. The SWC had the best association values with HDL when compared to the other adiposity variables, explaining $11.5 \%$ of the metabolic component variation. The SWC also revealed the most significant associations with BMI, explaining $74.1 \%$ of the variation in this variable. Systolic blood pressure and diastolic blood pressure were positively and significantly associated with all measures of central adiposity.

Table 3. Association between anthropometric indicators of obesity and metabolic variables in male adolescents $(n=92)$.

\begin{tabular}{|c|c|c|c|c|c|c|}
\hline Variables & & MWC & SWC & $\mathrm{BF} \%$ & BMI & WHtR \\
\hline \multirow{2}{*}{ HDL } & $\beta$ & $-0.428^{+}$ & $-0.487^{\dagger}$ & -0.129 & $-0.860^{\dagger}$ & $53.344 \ddagger$ \\
\hline & $\mathrm{R}^{2}$ & 0.106 & 0.115 & 0.010 & 0.082 & 0.048 \\
\hline \multirow{2}{*}{ SBP } & $\beta$ & $0.604^{\dagger}$ & $0.670^{+}$ & $0.535^{+}$ & $1.601^{\dagger}$ & $93.779^{\dagger}$ \\
\hline & $\mathrm{R}^{2}$ & 0.136 & 0.140 & 0.108 & 0.183 & 0.095 \\
\hline \multirow{2}{*}{ DBP } & $\beta$ & $0.335^{\dagger}$ & $0.391^{\dagger}$ & $0.234 \ddagger$ & $0.996^{\dagger}$ & $59.009^{+}$ \\
\hline & $\mathrm{R}^{2}$ & 0.082 & 0.094 & 0.041 & 0.140 & 0.074 \\
\hline \multirow{2}{*}{$\mathrm{BMI}$ ** } & $\beta$ & $0.007^{\dagger}$ & $0.008^{+}$ & $0.006^{\dagger}$ & _. & $1.384^{\dagger}$ \\
\hline & $\mathrm{R}^{2}$ & 0.722 & 0.741 & 0.458 & & 0.736 \\
\hline
\end{tabular}

${ }^{\dagger} p<0.001 .{ }^{\ddagger} p<0.05 .{ }^{* *}$ Transformed into a log. Note: HDL $=$ high-density lipoprotein; SBP = systolic blood pressure; $\mathrm{DBP}=$ diastolic blood pressure; $\mathrm{BMI}=$ body mass index; $\mathrm{MWC}=$ midpoint waist circumference; $\mathrm{SWC}=$ smallest waist circumference; $\mathrm{BF} \%$ = body fat $\%$; WHtR = waist-to-height ratio.

On average participants attended 32.6 intervention sessions (77.6\% of the total). Tables 4 and 5 , as well as Figure 1, show pre- and post-intervention comparisons for the 12 participants. There were no significant changes in anthropometric variables, except for height, which was statistically higher after the intervention $(p<0.001)$ (Table 4). However, the metabolic variables total cholesterol, LDL, and non-HDL were statistically lower $(p<0.05)$ after 14 weeks of the sports program. Besides that, the variables age and HDL demonstrated statistically significant increases $(p<0.05)$ when comparing the two study moments. 
Table 4. Anthropometric and metabolic variables at pre- and post-intervention $(n=12)$.

\begin{tabular}{ccccc}
\hline Variables & Pre- & Post- & $p$ Value & ES \\
\hline WHtR $^{*}$ & $0.42(0.39-0.56)$ & $0.42(0.37-0.53)$ & 0.071 & 0.36 \\
BF\% & $18.11( \pm 10.25)$ & $18.31( \pm 9.72)$ & 0.771 & 0.02 \\
MWC $(\mathrm{cm})^{*}$ & $74.47(67.5-99.0)$ & $72.57(69.1-92.8)$ & 0.875 & 0.03 \\
SWC $(\mathrm{cm})$ & $75.17( \pm 7.55)$ & $75.09( \pm 7.14)$ & 0.896 & 0.01 \\
SBP $(\mathrm{mmHg})$ & $114.5( \pm 12.19)$ & $111.25( \pm 10.2)$ & 0.082 & 0.29 \\
DBP $(\mathrm{mmHg})$ & $75.41( \pm 8.37)$ & $76.0( \pm 6.79)$ & 0.737 & 0.07 \\
HDL $(\mathrm{mg} / \mathrm{dL})$ & $38.53( \pm 6.19)$ & $52.10( \pm 14.25)$ & $0.004^{+}$ & 1.30 \\
TG $(\mathrm{mg} / \mathrm{dL})^{*}$ & $101.0(65.0-286.0)$ & $77.6(49.0-112.5)$ & 0.117 & 0.31 \\
FG $(\mathrm{mg} / \mathrm{dL})$ & $78.02( \pm 8.55)$ & $83.86( \pm 5.92)$ & 0.005 & 0.81 \\
Insulin $(\mathrm{mU} / \mathrm{L})$ & $5.91(1.91-25.4)$ & $6.90(2.58-19.7)$ & 0.347 & 0.19 \\
HOMA-IR * & $1.12(0.36-4.35)$ & $1.35(0.6-3.95)$ & 0.638 & 0.09 \\
TC $(\mathrm{mg} / \mathrm{dL})$ & $164.01( \pm 27.18)$ & $148.01( \pm 24.2)$ & $0.024^{+}$ & 0.62 \\
LDL $(\mathrm{mg} / \mathrm{dL})$ & $103.76( \pm 24.44)$ & $79.68( \pm 19.53)$ & $0.002^{+}$ & 1.1 \\
Non-HDL & $125.48( \pm 26.96)$ & $95.90( \pm 21.83)$ & $0.001^{+}$ & 1.2 \\
\hline
\end{tabular}

$+p<0.05$. Note: $\mathrm{BMI}=$ body mass index; WHtR = waist-to-height ratio; $\mathrm{BF} \%=$ body fat $\%$; MWC = midpoint waist circumference; $\mathrm{SWC}=$ smallest waist circumference; $\mathrm{SBP}=$ systolic blood pressure; $\mathrm{DBP}=$ diastolic blood pressure; HDL = high-density lipoprotein; TG = triglycerides; FG = fasting glucose; HOMA-IR = Homeostatic Model Assessment; TC $=$ total cholesterol; $\mathrm{LDL}=$ low density lipoprotein; Non-HDL = not HDL cholesterol; ES = effect size. ${ }^{*}$ Variables expressed as median (minimum and maximum); other variables: average ( \pm standard deviation).

Table 5. Energy expenditure, physical activity, and sedentary behavior before and during the intervention period.

\begin{tabular}{|c|c|c|c|c|c|}
\hline Variables & $\mathbf{n}$ & Pre- & Post- & $p$ Value & ES \\
\hline TEE (kcal/day) & 11 & $2963(2511-4423)$ & $3494(2886-4752)$ & $0.010^{+}$ & 0.55 \\
\hline BMR (kcal/day) * & 12 & $1822( \pm 212)$ & $1837( \pm 203)$ & 0.164 & 0.07 \\
\hline \multicolumn{6}{|l|}{ MVPA } \\
\hline $\min /$ day * & 11 & 72.5 (56.5-108.5) & $81.4(73-137)$ & $0.016+$ & 0.51 \\
\hline min/weekday & 11 & $88( \pm 19.9)$ & $100.6( \pm 19.5)$ & 0.070 & 0.64 \\
\hline $\mathrm{min} /$ weekend day * & 10 & $50.4( \pm 27.6)$ & $39.9( \pm 29.8)$ & 0.291 & 0.37 \\
\hline \multicolumn{6}{|l|}{ SB } \\
\hline $\mathrm{min} /$ week * & 11 & $598.4(492.7-673.3)$ & $587.8(498-922.6)$ & 0.929 & 0.01 \\
\hline min/weekday * & 11 & $650.2(464-682.6)$ & $596.7(488.8-1054)$ & 0.929 & 0.01 \\
\hline $\mathrm{min} /$ weekend day * & 9 & $520.5(380-668.5)$ & $498(265-552)$ & 0.594 & 0.13 \\
\hline
\end{tabular}

The intervention period significantly increased the weekly time spent in MVPA $(p=0.016)$ and the total daily energy expenditure $(p=0.010)$. Although not significant, there was a trend in increasing MVPA during weekdays $(p=0.07)$. No significant differences were found in the other variables, including SB (Table 5).

The prevalence of pre-MetS or MetS among intervention participants decreased by $41.6 \%$, reaching seven adolescents at the end of the program (Figure 1). The fasting glucose values were not shown since no participant showed high levels of this component during the first and second phases of the study. The intervention group reduced the MetS markers percentage for most of the evaluated parameters; except for the waist circumference measures.

Before starting the program, we calculated the maximal heart rate $(197 \mathrm{bpm})$ and resting heart rate (62 bpm) average. The average heart rate during the intervention session was $134 \pm 11.2 \mathrm{bpm}$. According to the heart rate values, the participants remained, on average, $25 \mathrm{~min}(\approx 42 \%)$ of the activity duration (60 min) within the moderate-to-vigorous intensity, with a mean of heart rate $157 \pm 3.8 \mathrm{bpm}$. This time is considered an adequate amount of time in MVPA, considering the recommendation that $50 \%$ of physical 
education classes (approximately $30 \mathrm{~min}$ ) should be performed at that intensity [36]. In the nutritional evaluation, no statistically significant differences were found between pre- and post-intervention.

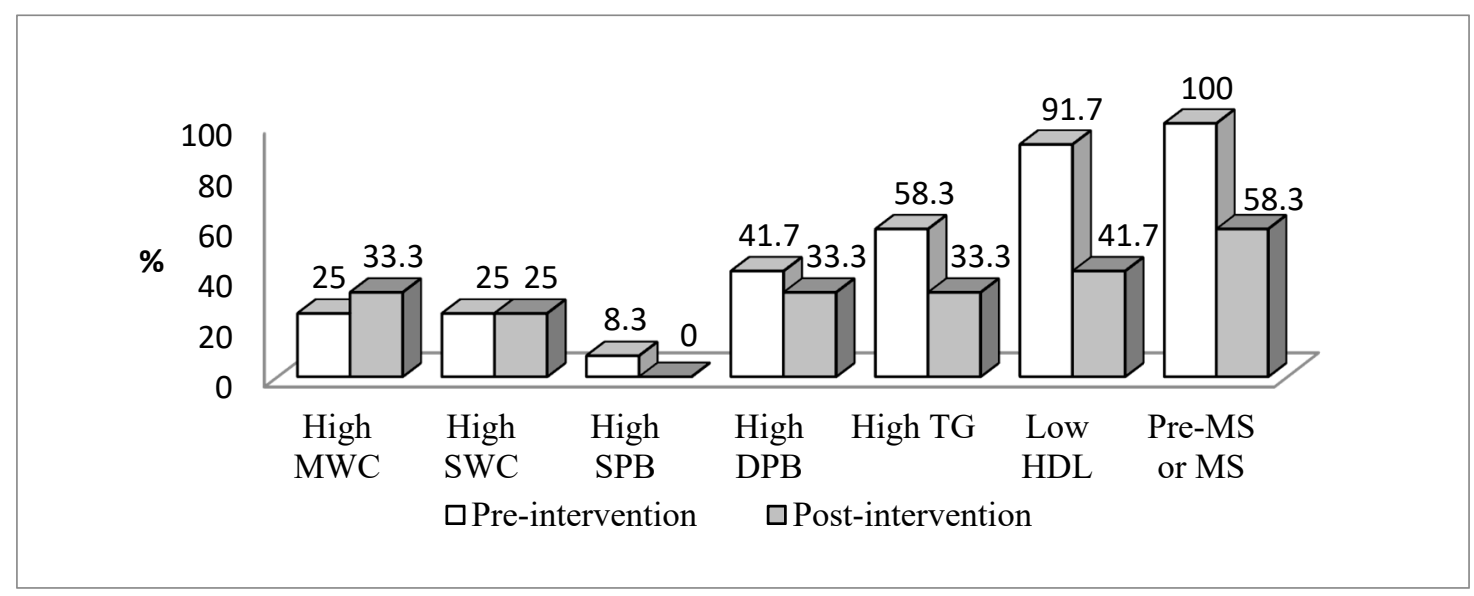

Figure 1. Changes in metabolic syndrome components in adolescents before and after 14 weeks of intervention.

\section{Discussion}

The definition of an internationally accepted criterion for MetS diagnosis in children and adolescents is a current debate by many researchers [37-39]. The diverse criteria and different cutoff points for each MetS component have provided discrepant prevalence among different countries [1,2,19]. However, regardless of the diagnostic method used, the harmful effects of pre-MetS and MetS on the cardiovascular health of children and adolescents, as well as their consequences in adult life, are well known $[7,40]$.

Our study diagnosed $4.3 \%$ of the total sample $(n=4)$ with MetS using the adult criteria, a prevalence similar to other studies involving adolescents [37,41]. However, a higher prevalence was found for pre-MetS, in which $34.8 \%(\mathrm{n}=32)$ of the adolescents had at least two of the diagnostic components. This early detection, or pre-MetS classification, is essential since individuals with pre-MetS are at high risk for developing MetS, as well as cardiovascular disease and type 2 diabetes mellitus [10]. The adolescents classified with pre-MetS or MetS already presented higher values for weight, BMI, MWC, SWC, systolic blood pressure, diastolic blood pressure, triglycerides, insulin, HOMA-IR, total cholesterol, LDL, and non-HDL cholesterol, and lower HDL values $(p<0.05)$. These results illustrate the metabolic impact of this condition and also suggest negative changes in lipid and glycolytic metabolism during adolescence. However, no significant differences in fasting glucose were identified between groups (with or without pre-MetS or MetS), since this variable typically exhibits a late response compared to the other MetS components [8]. Similarly, there were no significant differences in the MVPA between the groups, a fact that reinforces the multifactorial nature of MetS, which could be related to genetic, environmental, and behavioral aspects. These results, together, highlight the need to screen groups at risk for developing chronic noncommunicable diseases that could then allow the development of intervention strategies that meet the needs of this specific population.

The literature has been cohesive in treating anthropometric variables as metabolic predictors and cardiovascular disease risk factors in Brazilian children and adolescents [8,42]. Our results corroborated with such studies and suggested a significant association among the HDL, systolic blood pressure, diastolic blood pressure, and BMI with anthropometric indicators (Table 3). Further, SWC was the best predictor of lower HDL and higher BMI values, explaining $11.5 \%$ and $74.1 \%$ of the variability in these components, respectively, while BMI was the best predictor for elevated systolic blood pressure and diastolic blood pressure, explaining $18.3 \%$ and $14 \%$, respectively. These results reinforce the necessity and importance of anthropometric evaluation as a simple, low-cost technique that has high value in cardiovascular and metabolic risk prediction. 
The findings in this study agree with other investigations $[15-18,43]$ that present a short period of successful intervention to reduce the risk factors among adolescents. After 14 weeks of these sports intervention, the presence of risk factors for MetS decreased, resulting in a reduction of $41.7 \%$ in the diagnosis of pre-MetS or MetS. By the end of the intervention, only seven participants remained diagnosed with pre-MetS or MetS (Figure 1). In addition, the results indicated that the sports program was effective in improving the adolescents' lipid profiles, with a significant decrease $(p<0.05)$ in several risk factors, including total cholesterol, LDL, non-HDL cholesterol; as well as increase in protective factors such as HDL, daily MVPA, and total daily energy expenditure (Tables 4 and 5).

Studies have identified anthropometric variables as significant risk factors and health indicators, showing that modifications in these variables may reduce MetS diagnoses [43,44]. Despite the reduction in the pre-MetS or MetS prevalence and positive results in cardiometabolic biomarkers, the intervention did not result in positive changes in anthropometric measures. This fact suggests that the duration of the intervention may not have been enough to promote changes in these measures, reinforced by the literature demonstrating improvements in anthropometric measures only in interventions of at least 6 months [6,38]. Intervention studies lasting approximately 14 weeks $[15,17]$ have reported increases in some anthropometric measures, such as BMI and waist circumference; however, the interventions included aerobic and resistance exercises, unlike our study, which used sports activities characteristic of the school environment primarily.

The positive lipid modifications following the intervention confirm the influence of MVPA on adolescents' metabolic health, as highlighted in the literature $[45,46]$. It is valid to consider that the benefits are not restricted to the minimum recommended dose of $60 \mathrm{~min}$ of daily MVPA since the adolescents evaluated had mean baseline values higher than 60 min daily. After the intervention, they significantly increased the regular MVPA time (Table 5), emphasizing that the higher MVPA dose leads to better health outcomes, corroborating the WHO's statement [13].

Another critical study observation is the amount of time the adolescents spent in SB, close to $10 \mathrm{~h}$ daily (approximately 598 and $587 \mathrm{~min}$, pre- and post-intervention, respectively) (Table 5). This high level of SB time alerted us to the harmful interactions of this behavior on body composition and metabolic variables. The literature points to deleterious effects of spending more than $2 \mathrm{~h}$ daily in this type of behavior in children and adolescents $[14,15]$. Studies involving pediatric population suggest a significant association between SB and BMI [47], waist circumference [47], triglycerides [48], and HDL [49]. However, children and adolescents who frequently interrupt their time in SB may be at lesser risk, since small breaks in SB appear to be sufficient to reduce cardiovascular risk [49]. Thus, intervention programs in adolescence, especially among those in a full-time school, should address the reduction of this behavior and create strategies to promote physical activity, even at light intensities, as an alternative to SB.

The intervention program was not intended to establish an intensity range to be maintained by adolescents. Despite that, the degree of involvement with the sports activities promoted voluntary, significant time in moderate to vigorous intensity. Approximately $42 \%$ ( $25 \mathrm{~min}$ ) of the daily recommendation of MVPA was obtained during this intervention. Therefore, the physical activity ludic aspect should be contemplated in future intervention programs, especially in the school environment, to promote the adoption and maintenance of an active lifestyle by adolescents [50].

We believe that the results achieved by this study should be interpreted as the exclusive result of the physical activity promotion since no statistically significant differences were found in the frequency of food consumption. This fact was already expected due to the standardization of food provided in a boarding school environment, where most meals reported by the adolescents were those offered by the institution.

The main limitations of this study were the male participation restriction and the small number of participants in the intervention phase. However, the originality of the study stands out because, to the best of our knowledge, no intervention studies based on the promotion of recreational sports activities with Brazilian adolescents were found in the literature. As sports activities are inherent to the 
everyday life of schoolchildren, this increases the ecological validity of our findings. This type of group intervention should be considered as a viable, easy-to-perform, low-cost, and extremely motivational alternative for this particular population; when compared to interventions restricted to aerobic and resistance exercises program performed in closed and controlled environments. Lastly, it is suggested that future intervention studies focused on sports activities should extend the duration longer than 14 weeks and include female adolescents. We also suggested that interventions should be tailored according to the needs of this population.

\section{Conclusions}

This study suggests a high prevalence of pre-MetS or MetS among adolescents. The new pre-MetS classification was meaningful in identifying those adolescents at risk for developing MetS and should be incorporated in this population. Following the intervention, reductions in risk factors for MetS were observed, mainly in the lipid measures. The intervention reinforces that recreational sports activities contributed to increasing time spent in MVPA. Besides that, it highlight that effects are essential as preventive action and non-pharmacological therapeutic procedures for adolescents at risk of developing chronic non-communicable diseases to improve their metabolic profile. Positive lifestyle changes by means of increasing MVPA and reducing SB are the bases for MetS prevention in this population.

Author Contributions: Conceptualization, F.F and P.R.A.; methodology, R.F.; formal analysis, F.F. and R.F.; project administration, R.F. and P.R.A.; data curation, F.F. and R.F.; supervision, P.R.A. and J.C.M.; writing-original draft preparation, F.F., C.H. and R.F.; writing-review and editing, F.F., C.H., A.A., J.C.M. and P.R.A. All authors have read and agreed to the published version of the manuscript.

Acknowledgments: The authors thank the Fundação Arthur Bernardes (FUNARBE) for financial support that allowed them to perform the blood tests in this study.

Conflicts of Interest: The authors declare no conflict of interest.

\section{References}

1. Zimmet, P.; Alberti, A.G.; Kaufman, F.; Tajima, N.; Silink, M.; Arslanian, S.; Wong, G.; Bennett, P.; Shaw, J.; Caprio, S.; et al. The metabolic syndrome in children and adolescents. Lancet 2007, 369, 2059-2061. [CrossRef]

2. Cook, S.; Weitzman, M.; Auinger, P.; Nguyen, M.; Dietz, W.H. Prevalence of a metabolic syndrome phenotype in adolescents: Findings from the third National Health and Nutrition Examination Survey, 1988-1994. Arch. Pediatr. Adolesc. Med. 2003, 157, 821-827. [CrossRef] [PubMed]

3. Alberti, K.G.; Eckel, R.H.; Grundy, S.M.; Zimmet, P.Z.; Cleeman, J.I.; Donato, K.A.; Fruchart, J.; James, W.P.T.; Loria, C.M.; Smith, S.C., Jr. Harmonizing the metabolic syndrome: A joint interim statement of the International Diabetes Federation Task Force on Epidemiology and Prevention; National Heart, Lung, and Blood Institute; American Heart Association; World Heart Federation; International Atherosclerosis Society; and International Association for the Study of Obesity. Circulation 2009, 120, 1640-1645. [PubMed]

4. Kuschnir, M.C.; Bloch, K.V.; Szklo, M.; Klein, C.H.; Barufaldi, L.A.; Abreu, G.A.; Schaan, B.; Veiga, G.V.; Silva, T.L.N.; Vasconcellos, M.T.L.; et al. ERICA: Prevalence of metabolic syndrome in Brazilian adolescents. Rev. Saude Publica 2016, 50, 11. [CrossRef]

5. Stabelini Neto, A.; Bozza, R.; Ulbrich, A.; Mascarenhas, L.P.; Boguszewski, M.C.; Campos, W. Metabolic syndrome in adolescents of different nutritional status. Arq. Bras. Endocrinol. Metabol. 2012, 56, 104-109. [CrossRef]

6. Caranti, D.A.; de Mello, M.T.; Prado, W.L.; Tock, L.; Siqueira, K.O.; de Piano, A.; Lofrano, M.C.; Cristofalo, D.M.; Lederman, H.; Tufik, S.; et al. Short- and long-term beneficial effects of a multidisciplinary therapy for the control of metabolic syndrome in obese adolescents. Metabolism 2007, 56, 1293-1300. [CrossRef]

7. Araki, M.V.R.; Martins, I.C.R.; Barros, C.; Santos, E.G. Non-HDL-cholesterol in children and adolescents. Sci. Plena 2013, 9, 1-8.

8. Conceicao-Machado, M.E.; Silva, L.R.; Santana, M.L.; Pinto, E.J.; Silva, R.D.; Moraes, L.T.; Couto, R.D.; Assis, A.M. Hypertriglyceridemic waist phenotype: Association with metabolic abnormalities in adolescents. J. Pediatr. 2013, 89, 56-63. [CrossRef] 
9. De las Fuentes, L.; Brown, A.L.; Mathews, S.J.; Waggoner, A.D.; Soto, P.F.; Gropler, R.J.; Dávila-Román, V.G. Metabolic syndrome is associated with abnormal left ventricular diastolic function independent of left ventricular mass. Eur. Heart J. 2007, 28, 553-559. [CrossRef]

10. Yin, Q.; Chen, X.; Li, L.; Zhou, R.; Huang, J.; Yang, D. Apolipoprotein B/apolipoprotein A1 ratio is a good predictive marker of metabolic syndrome and pre-metabolic syndrome in Chinese adolescent women with polycystic ovary syndrome. J. Obstet. Gynaecol. Res. 2013, 39, 203-209. [CrossRef]

11. Machado-Rodrigues, A.M.; Leite, N.; Coelho e Silva, M.J.; Valente-dos-Santos, J.; Martins, R.A.; Mascarenhas, L.P.; Boguszewski, M.C.; Padez, C.; Malina, R.M. Relationship between metabolic syndrome and moderate-to-vigorous physical activity in youth. J. Phys. Act. Health 2015, 12, 13-19. [CrossRef] [PubMed]

12. Durstine, J.L.; Gordon, B.; Wang, Z.; Luo, X. Chronic disease and the link to physical activity. J. Sport Health Sci. 2013, 2, 3-11. [CrossRef]

13. World Health Organization. Global Recommendations on Physical Activity for Health; World Health Organization: Geneva, Switzerland, 2010.

14. Tremblay, M.S.; LeBlanc, A.G.; Kho, M.E.; Saunders, T.J.; Larouche, R.; Colley, R.C.; Goldfield, G.; Connor Gober, S. Systematic review of sedentary behaviour and health indicators in school-aged children and youth. Int. J. Behav. Nutr. Phys. Act. 2011, 8, 98. [CrossRef] [PubMed]

15. Farias Júnior, J.C. (In) Atividade física e comportamento sedentário: Estamos caminhando para uma mudança de paradigma? Rev. Bras. Ativ. Fis. Saúde 2011, 16, 279-280.

16. Bianchini, J.A.; da Silva, D.F.; Nardo, C.C.; Carolino, I.D.; Hernandes, F.; Nardo, N., Jr. Multidisciplinary therapy reduces risk factors for metabolic syndrome in obese adolescents. Eur. J. Pediatr. 2013, 172, $215-221$. [CrossRef]

17. Gronbaek, H.; Lange, A.; Birkebaek, N.H.; Holland-Fischer, P.; Solvig, J.; Horlyck, A.; Kristensen, K.; Rittig, S.; Vilstrup, H. Effect of a 10-week weight loss camp on fatty liver disease and insulin sensitivity in obese Danish children. J. Pediatr. Gastroenterol. Nutr. 2012, 54, 223-228. [CrossRef]

18. Lee, S.; Bacha, F.; Hannon, T.; Kuk, J.L.; Boesch, C.; Arslanian, S. Effects of aerobic versus resistance exercise without caloric restriction on abdominal fat, intrahepatic lipid, and insulin sensitivity in obese adolescent boys: A randomized, controlled trial. Diabetes 2012, 61, 2787-2795. [CrossRef]

19. De Ferranti, S.D.; Gauvreau, K.; Ludwig, D.S.; Neufeld, E.J.; Newburger, J.W.; Rifai, N. Prevalence of the metabolic syndrome in American adolescents: Findings from the Third National Health and Nutrition Examination Survey. Circulation 2004, 110, 2494-2497. [CrossRef]

20. Matthews, D.R.; Hosker, J.P.; Rudenski, A.S.; Naylor, B.A.; Treacher, D.F.; Turner, R.C. Homeostasis model assessment: Insulin resistance and beta-cell function from fasting plasma glucose and insulin concentrations in man. Diabetologia 1985, 28, 412-419. [CrossRef]

21. Friedewald, W.T.; Levy, R.I.; Fredrickson, D.S. Estimation of the concentration of low-density lipoprotein cholesterol in plasma, without use of the preparative ultracentrifuge. Clin. Chem. 1972, 18, 499-502.

22. Srinivasan, S.R.; Myers, L.; Berenson, G.S. Distribution and correlates of non-high-density lipoprotein cholesterol in children: The Bogalusa Heart Study. Pediatrics 2002, 110, 29. [CrossRef] [PubMed]

23. The Brazilian Society of Cardiology. VII Brazilian Guidelines on Hypertension. Arq. Bras. Cardiol. 2016, 107, 1-83.

24. Ten, S.; Maclaren, N. Insulin resistance syndrome in children. J. Clin. Endocrinol. Metab. 2004, 89, $2526-2539$. [CrossRef] [PubMed]

25. International Society for the Advancement of Kinanthropometry. International Standards for Anthropometric Assessment; National Library of Australia: Adelaide, Australia, 2001.

26. De Onis, M.; Onyango, A.W.; Borghi, E.; Siyam, A.; Nishida, C.; Siekmann, J. Development of a WHO growth reference for school-aged children and adolescents. Bull. World Health Organ. 2007, 85, 660-667. [CrossRef] [PubMed]

27. World Health Organization. WHO Technical Report Series 894 Obesity: Preventing and Managing the Global Epidemic; World Health Organization: Geneva, Switzerland, 2000.

28. Slaughter, M.H.; Lohman, T.G.; Boileau, R.A.; Horswill, C.A.; Stillman, R.J.; Van Loan, M.D.; Bemben, D.A. Skinfold equations for estimation of body fatness in children and youth. Hum. Biol. 1988, 60, 709-723. [PubMed] 
29. Going, S.B.; Lohman, T.G.; Cussler, E.C.; Williams, D.P.; Morrison, J.A.; Horn, P.S. Percent body fat and chronic disease risk factors in U.S. children and youth. Am. J. Prev. Med. 2011, 41, 77-86. [CrossRef]

30. Mirwald, R.L.; Baxter-Jones, A.D.; Bailey, D.A.; Beunen, G.P. An assessment of maturity from anthropometric measurements. Med. Sci. Sports Exerc. 2002, 34, 689-694.

31. Tanaka, H.; Monahan, K.D.; Seals, D.R. Age-predicted maximal heart rate revisited. J. Am. Coll. Cardiol. 2001, 37, 153-156. [CrossRef]

32. Rich, C.; Geraci, M.; Griffiths, L.; Sera, F.; Dezateux, C.; Cortina-Borja, M. Quality control methods in accelerometer data processing: Defining minimum wear time. PLoS ONE 2013, 8, 67206. [CrossRef]

33. Puyau, M.R.; Adolph, A.L.; Vohra, F.A.; Butte, N.F. Validation and calibration of physical activity monitors in children. Obes. Res. 2002, 10, 150-157. [CrossRef]

34. Brooks, G.A.; Butte, N.F.; Rand, W.M.; Flatt, J.P.; Caballero, B. Chronicle of the Institute of Medicine physical activity recommendation: How a physical activity recommendation came to be among dietary recommendations. Am. J. Clin. Nutr. 2004, 79, 921-930. [CrossRef] [PubMed]

35. Schofield, W.N. Predicting basal metabolic rate, new standards and review of previous work. Hum. Nutr. Clin. Nutr. 1985, 39, 5-41. [PubMed]

36. Khan, L.K.; Sobush, K.; Keener, D.; Goodman, K.; Lowry, A.; Kakietek, J.; Zaro, S.; Centers for Disease Control and Prevention. Recommended community strategies and measurements to prevent obesity in the United States. MMWR Recomm. Rep. 2009, 58, 1-26. [PubMed]

37. Moraes, A.C.; Fulaz, C.S.; Netto-Oliveira, E.R.; Reichert, F.F. Prevalence of metabolic syndrome in adolescents: A systematic review. Cad. Saude Publica 2009, 25, 1195-1202.

38. Wickham, E.P.; Stern, M.; Evans, R.K.; Bryan, D.L.; Moskowitz, W.B.; Clore, J.N.; Laver, J.H. Prevalence of the metabolic syndrome among obese adolescents enrolled in a multidisciplinary weight management program: Clinical correlates and response to treatment. Metab. Syndr. Relat. Disord. 2009, 7, 179-186. [CrossRef]

39. Andaki, A.C.; Tinoco, A.L.; Mendes, E.L.; Andaki Junior, R.; Hills, A.P.; Amorim, P.R. Different waist circumference measurements and prediction of cardiovascular risk factors and metabolic syndrome in children. Obes. Res. Clin. Pract. 2012, 6, 91-174. [CrossRef]

40. Barzin, M.; Asghari, G.; Hosseinpanah, F.; Mirmiran, P.; Azizi, F. The association of anthropometric indices in adolescence with the occurrence of the metabolic syndrome in early adulthood: Tehran Lipid and Glucose Study (TLGS). Pediatr. Obes. 2013, 8, 170-177. [CrossRef]

41. Sangun, O.; Dundar, B.; Kosker, M.; Pirgon, O.; Dundar, N. Prevalence of metabolic syndrome in obese children and adolescents using three different criteria and evaluation of risk factors. J. Clin. Res. Pediatr. Endocrinol. 2011, 3, 70-76. [CrossRef]

42. Andaki, A.C.; Tinoco, A.L.; Mendes, E.L.; Andaki Junior, R.; Hills, A.P.; Amorim, P.R. Anthropometry and physical activity level in the prediction of metabolic syndrome in children. Public. Health Nutr. 2014, 17, 2287-2294. [CrossRef]

43. Leite, N.; Milano, G.E.; Cieslak, F.; Lopes, W.A.; Rodacki, A.; Radominski, R.B.I. Effects of physical exercise and nutritional guidance on metabolic syndrome in obese adolescents. Rev. Bras. Fisioter. 2009, 13, 73-81. [CrossRef]

44. Thomas, N.E.; Cooper, S.M.; Williams, S.P.; Baker, J.S.; Davies, B. Relationship of fitness, fatness, and coronary-heart-disease risk factors in 12- to 13-year-olds. Pediatr. Exerc. Sci. 2007, 19, 93-101. [CrossRef] [PubMed]

45. Reichert, F.F.; Hallal, P.C.; Wells, J.C.; Horta, B.L.; Ekelund, U.; Menezes, A.M. Objectively measured physical activity in the 1993 Pelotas (Brazil) birth cohort. Med. Sci. Sports Exerc. 2012, 44, 2369-2375. [CrossRef] [PubMed]

46. Guinhouya, B.C.; Samouda, H.; de Beaufort, C. Level of physical activity among children and adolescents in Europe: A review of physical activity assessed objectively by accelerometry. Public Health 2013, 127, 301-311. [CrossRef] [PubMed]

47. Herman, K.M.; Chaput, J.P.; Sabiston, C.M.; Mathieu, M.E.; Tremblay, A.; Paradis, G. Combined physical activity/sedentary behaviour associations with indices of adiposity in 8- to 10-year-old children. J. Phys. Act. Health 2015, 12, 20-29. [CrossRef] [PubMed] 
48. Vaisto, J.; Eloranta, A.M.; Viitasalo, A.; Tompuri, T.; Lintu, N.; Karjalainen, P.; Lampinen, E.K.; Ågren, J.; Laaksonen, D.E.; Lakka, H.M.; et al. Physical activity and sedentary behaviour in relation to cardiometabolic risk in children: Cross-sectional findings from the Physical Activity and Nutrition in Children (PANIC) Study. Int. J. Behav. Nutr. Phys. Act. 2014, 11, 55. [CrossRef] [PubMed]

49. Cliff, D.P.; Jones, R.A.; Burrows, T.L.; Morgan, P.J.; Collins, C.E.; Baur, L.A.; Okely, A.D. Volumes and bouts of sedentary behavior and physical activity: Associations with cardiometabolic health in obese children. Obesity 2014, 22, 112-118. [CrossRef] [PubMed]

50. Faria, F.R.; Canabrava, K.L.R.; Amorim, P.R.S. Nível de Atividade Física durante o recreio escolar em escola pública e particular. Revisita Bras. Cienc. E Mov. 2013, 21, 90-97. [CrossRef]

(C) 2019 by the authors. Licensee MDPI, Basel, Switzerland. This article is an open access article distributed under the terms and conditions of the Creative Commons Attribution (CC BY) license (http://creativecommons.org/licenses/by/4.0/). 